\title{
The Uninhibited Evolution of the Human Persona: A Transhumanistic Study of Anil Menon's The Beast with Nine Billion Feet
}

Narendiran $\mathrm{S}^{\dagger}$ and Bhuvaneswari $\mathrm{R}^{\text {* }^{*}}$

\section{Abstract}

Debates on intuition about transformed humankind in the future have led to the conception of transhumanism. It is a new philosophical movement to express the ideology that humanism will evolve by employing science and technology. Supporters of transhumanism believe that scientific aid in the evolution of humans will take them beyond the bounds of physical and mental limitations; eventually, it will make them immortals. The influence of transhumanism in literature has given birth to seminal works of art, particularly science fiction. Anil Menon's The Beast with Nine Billion Feet is one such novel which sprang out the moral issues due to the rapid growth of science and technology affecting social, cultural, and political scenarios in India. The story is about genetic engineering and its impact on the socio-political problems. In addition to unfolding the threats and opportunities of transhumanism, the novel also touches on the issues of young adults like acquiring autonomy and finding their true identity. This study attempts to bring out the trepidation and chaos resultant of the period of transition and the multiple challenges and threats to the human race.

Keywords: Transhumanism; Evolution; Technology; Identity and Young Adult

\footnotetext{
${ }^{\dagger}$ Research Scholar, School of Social Sciences and Languages, Vellore Institute of Technology, Chennai, Vandalur, Kelambakkam Road, Chennai-600127, Tamil Nadu, India Email: narendiran10@gmail.com

${ }^{*}$ Corresponding Author Email: bhuvanadoss@yahoo.co.in

${ }^{¥}$ Assistant Professor (Sr.), School of Social Sciences and Languages, Vellore Institute of Technology, Chennai , Vandalur, Kelambakkam Road, Chennai-600127, Tamil Nadu, India

(C) 2020 S\&R. This is an Open Access article distributed under the terms of the Creative Commons Attribution License (http://creativecommons.org/licenses/by/2.0), which permits unrestricted use, distribution, and reproduction in any medium, provided the original work is properly cited.
} 


\section{Introduction}

The beginning of the $21^{\text {st }}$ Century was marked by the rapid development of new branches of science, which started to challenge traditional convictions about a significant number of anthropological issues. It became clear that due to the appearance of new technologies, people acquire tools that can potentially improve human bodies and to increase their intellectual abilities significantly. Alongside with technologies, a new philosophical movement started to develop, and it received the name, transhumanism. This movement is based on the belief that people are capable of improving themselves and break free the biological limitations of their bodies employing technological innovations and scientific progress. At the beginning of the $21^{\text {st }}$ Century, transhumanism has become very popular and this strength finds reflection in literary works of various writers across the globe. One such book is The Beast with Nine Billion Feet created by Anil Menon. The novel is about two siblings, Tara and Aditya, and discusses a significant number of new ethical issues, which were brought in by the rapid growth of technology and its undeniable impact on both individual and social groups. The study begins with the definition and history of transhumanism and attempts to explore the ideas on transhumanism and its implications in the select novel. It also highlights its influence on young adults in an era of rapid scientific development and the hazards and dangers of genetic mutation.

\section{History and Definition of Transhumanism}

Though the term "transhumanism" has appeared relatively recently, it is far from being absolutely new. For the first time, the word "transhuman" was used by Dante Alighieri (2003) in the "Divine Comedy" (1312). Later, it was widely used by the Enlightenment thinkers, which provided a healthy dose of postmodern relativism. It was a period characterized by materialistic empiricism. As the scholars indicate, "The Enlightenment thinkers attempted to move past the idea of human nature as being defined by God-given immortal souls inhabiting flesh, to the view that we are rational minds emerging out of and transforming nature" (Hughes, 2013, p. 227). In 1748, the work "L'Homme Machine" ("Man a Machine") was written by doctor and philosopher Julien Offray de La Mettrie, who wrote that "people, by and large, are only animals and machines." (de La Mettrie, J. O. 1912). In general, the scholars are unanimous in their conclusions stating that, "Transhumanism has inherited many ideological contradictions from Enlightenment philosophy. These include the conflict between atheism and the belief that intelligence could become godlike, or between teleological technooptimism and the rationalist acknowledgement that the future is uncertain" (Hughes, 2013, p. 229). All of these ideas created the basis, which successfully evolved into a concept in the subsequent epochs.

In the modern sense, the term "transhumanism" is found in the work of evolutionary biologist Julian Huxley, namely in his treatise Religion without Revelation. The spirit of his era, was marked by the intrusion of natural sciences in different spheres of human thinking, emergence of genetics as an independent scientific theory and the beginning of the liberation of everyday life from the influence of religion. Huxley presented "transhumanism" as a new ideology and as a new "faith" for humanity based on the scientific and technological revolution. (Huxley, 1967)

The modern wave of scientific and technological revolution infused interest in the ideas of transhumanism. The year 1957, the year in which Julian Huxley's essay Transhumanism was published is commonly considered to be the date of birth of the term "transhumanism." Since 1966, the Iranian-American futurologist FM2030 (Fereidoun M. Esfandiary) (1989) has promoted transhumanist ideas. He defined transhumanists as people with a unique world view aimed at the improvement of their lifestyle; people who use modern achievements of science and technology for the transition to the "posthuman" phase of existence. In "Wheretotranshumanism? The Literature 
Reaches a Critical Mass", after the perusal of the website on World Transhumanist Association, Nicholas Agar, finds out that the association has got a global membership of 3,744 as of 2007 . This would pose a view that transhumanism is not widely welcomed. However, Nicholas emphasises that "transhumanists are not marginalized, technology obsessed Trekkies. They present their view about where we should be headed with a keen awareness of how we might get there". (Agar, 2007)

While the majority of the mentioned thinkers concentrate on the positive outcome of transhumanism, Max More became one of the first philosophers who brought to light an immensely important issue. He pondered upon the influence of transformation on the person and stated that, "Some persons lack a strong core of values. These persons would give up their identity through transforming... Those who value self-transformation strongly can undergo more changes in other characteristics while maintaining identity" (as cited in More, 2013, p. 230). According to More's point of view, any radical enhancement would eventually break personal identity and can bring more harm than benefit.

One more problem mentioned by the opponents of human modification is that "Transhumanists also accept the plausibility, even inevitability, of multiple copies of personalities which would all feel identity with the original prior person. While most transhumanists do not see the multiplication of selves as problematic, it is usually considered incompatible with the assumed transitive unity of identity over time" (Hughes, 2013, p. 231). The main message of this citation can be used as the basis of the antitranshumanism campaign. Since people become copies of one original source, humanity will lose its uniqueness. By far, this is the main challenge of transhumanism from an anthropological point of view. Such a notion as diversity will disappear since everybody will look, behave, and even think in the same way.

Hughes also discusses another important anthropological issue and this is the role of an individual in the society. He writes that, "I have argued that radical longevity and cognitive enhancement will push liberal democratic society to adopt post-liberal individualist moral, legal, and political frameworks that do not assume personal identity, although what the contours of such frameworks might be I cannot say. It is hard to discern, however, what meaning 'liberty, equality, and fraternity' would have without the convenient fiction of autonomous individuals as citizens" (Hughes, 2013, p. 231). Previously, the development of human civilization was viewed as the movement from ungoverned groups of individuals towards more complicated structures that founded the basis of states. However, this idea is challenged by transhumanists since, alongside the new physical possibilities, people acquire more freedom. As a result, there is no need to live according to the commonly accepted rules.

According to Mercer (2014), transhumanism is "a philosophical movement that advocates for the transformation of the human condition by developing and making widely available sophisticated technologies to greatly enhance human intellect and physiology" (310). It denotes the ideological-related concepts of human evolution. Accordingly:

in the future the Homo sapiens era will be replaced by a more perfect humanity, which, with the help of science and advanced technologies, will get rid of most of the limitations and problems, its own body. Wherever natural evolution has reached its limit, artificial evolution will start, controlled by the people themselves (Transhumanism: into the future by the razor's edge. Idea and prospects. - Steemit, 2019).

In a broad sense, transhumanism is a transition from an ordinary person to a better version of humans or a posthuman. Dow and Wright (2010), highlights the probable function of transhumans posted in posthuman.com:

transhumanism offers 'a vision of how we might concretely use technology and other means to change what we are - not to replace ourselves with something else, but to realize our potential to become something more than we currently are. (Dow \& Wright, 2010) 
This is a worldview based on scientific principles, which states that even though man is the crown of evolution, he still can undergo improvisation in all spheres. Rational-minded transhumanists understand that people are imperfect and can be made stronger and more improvised with the help of technology and science. From ancient times, people have dreamt of overcoming the limits of their abilities.

Despite all these hopes and longing, in the previous epochs, human beings had no tools which could enable them to improve their physical prowess. New opportunities were provided by the development of science and the appearance of such branches as cybernetics, nanotechnology, pharmacology, computer modelling, neurotechnology, and many others. It is believed that these sciences will eventually convert the mind into a virtual network, and it means that biological death will end the life of the body but not the mind. Due to the development of the aforesaid technologies, scientists can insert a copy of the individual brain inside the computer, and it can function there. Elaine Graham, views that such technological trends as a colonisation of "the 'human' by the 'mechanical'... 'transhumanism', regards technology as a vehicle by which humanity will perfect itself, and celebrates the seemingly unlimited potential of technoscience for building a new world order"(Graham, 2002, p. 66)

Though there is still no direct way to overcome the limitations of people's biological nature, the works of writers like Anil Menon demonstrate that 'rather soon a dream can become a reality'. The characters, he describes, live not in a faraway future, Menon places the main events in 2040 and it means that all innovations and changes are almost palpable. Furthermore, some of the technologies described in the book have been already introduced. For instance, genetically modified crops are widely used in many regions in the world. The same can be said about the use of implants and artificial body organs. "Transhumanists see the body as a machine, the brain as a computer. These are seductive metaphors, especially for computer engineers. They imply that with the right tools we might be able to fix, improve, and upgrade ourselves. And if trans-humanists have their way, the specimens in that exhibition will soon be outdated models of the human body" (Gelles, 2020) so, it is possible to argue that transhumanism is not a distant future but an upcoming reality.

\section{Young Adult Literature and The Beast with Nine Billion Feet}

In addition to being one of the most successful books disclosing the main benefits and threats of transhumanism, The Beast with Nine Billion Feet is a novel about the problems of young adults. It will not be an exaggeration to argue that Anil Menon's work has been written for the mentioned group of readers because it represent the future world from Tara's and Adi's perspectives. Since the protagonists of the analysed novel are two teenagers, it is evident that the author touches the problems which worry them. It remains real for young adults, no matter in whichever epoch they live or whichever region they represent.

According to the critics these problems include:

the relationship between embodiment and cognition; the independent and unified humanist subject versus the fragmented, destabilized and collective posthuman subject; and the significance of the cyborg, a figure that plays a pivotal role in posthuman ideology because of the way in which it subverts binary distinctions between human/machine and real/artificial (Flanagan, 2014, p. 15). While these themes are typical for almost all science fiction works, young adult literature discloses several other issues which are important for teenagers and adolescents. One of them is acquiring personal autonomy and finding their true identity.

The researchers indicate that:

the concept of free will or agency (which can be loosely defined as the ability of action to transcend its material context) is problematic when applied to children and adolescents, who are normally subject to the control of their parents or legal guardians and cannot experience or 
attain complete personal autonomy (Flanagan, 2014, p.17).

In the novel, the brother and the sister seek to gain their personal independence. Their understanding is a way towards an absolute autonomy from adults who try to control them. This striving is especially noticeable in case of Adi, who considers himself to be grown up enough to lead an independent life.

At the beginning of the novel, the author indicates that both siblings live with their aunt Sita, and he does not provide any information about their parents. While Tara has better relationship with the aunt and appreciates her help, Adi seems to be a real rebel who has no desire to meet the requirements of the woman who had to take care of him. Later, it becomes clear that the children have to live without their parents because their mother dies when Tara was born, and their father was declared to be a terrorist. Even though the father was a talented biologist, his activities enabled people to get access to the free seeds and other achievements of genetics. This posed a threat for the international corporations planning to monopolise Indian market. As a result, Sivanbhau had to leave his children and hide from being persecuted.

The lack of parental care and control had an undeniable impact on Tara and Adi. Both of the children were proud of their father, and they considered him to be a genius. However, despite a high evaluation of his achievements they had to cope with their low social status, a constant lack of money, and the unwillingness of other people to communicate with them. Still, they had a hope that one day their father would return from the exile and it would mean the improvement of their living conditions. Meanwhile, Adi failed the majority of tests and had to take humiliating jobs at BodZ (it is the name of a virtual reality company where Adi takes up a menial job) in order to receive some money. He also got deeply involved in virtual world in which he could create any illusions.

The interconnection between human beings and machines possessing artificial intelligence is one more problem which is often represented in the science fiction books created for young adults. According to Hayles (1993):

An essential component of coming to terms with the ethical implications of intelligent machines is recognizing the mutuality of our interactions with them, the complex dynamics through which they create us even as we create them (p.243).

The mentioned problem is of major importance for Adi, who is obsessed with virtual reality to such an extent that it hampers his working obligations.

While Adi found some consolation in the virtual world, Tara chose a different strategy she became a voracious reader. This activity helped her to cope with her loneliness and to get good education that could become the basis of her future success. In this way, Anil Menon clearly points out that in an era of rapid scientific development, children and teenagers have two main strategies for development. They either plunge into the virtual world with its numerous attractions or concentrate on studying and selfimprovement. In the first case, children risk suffering from the absence of social connections and real-life communication. In the second case, they risk becoming too concentrated on getting success in the educational sphere, which can impact their psychological wellbeing.

\section{Ria and Francis as New People}

In addition to Tara and Adi, there are two more teenagers, Ria and Francis, the foreigners arrived in India with their mother. They are immensely impressed by the beauty of the natural environment. Unlike Tara and Adi, Ria and Francis represent the privileged class of children representative of a higher social status because of the elevated social status of their mother. They live in a massive house with their own swimming pool and a car which is powered by artificial intelligence. Besides, their mother seems to be extremely beautiful, clever, and caring. Compared to Sivan-bhau's children, their life reminds a fairy tale in which all desires and dreams easily come true.

The development of the plot demonstrates that this dreamlike picture is nothing than an illusion. 
It turns out that Ria and Francis did not come from Sweden. They were born in Nurth (it is an artificial island where Mandria's genetic coding company is located), and they represent a new generation of human beings who differ much from all others. In her conversation with Tara, Ria mentions that "Nurth has only been around for thirty or forty years... everybody over twenty anyway, came from somewhere else... But the kids are different. We were born on Nurth. They call us the novae, the new ones" (Menon, 2009, p. 63). The children born on this artificial island have a specific feature - the absence of the navel. It means that the children were not born of their mothers but created artificially with the help of technology.

The representation of children as those who were created in the result of scientific experiments of the use of technologies is typical for young adult literature. The critics indicate that, "[i]n some cases, these protagonists have been born as a result of genetic engineering (and therefore played no role in the decision)" (Flanagan, 2014, p. 17). Precisely, this approach is shown in the case of Ria and Francis. Tara, she is represented as a normal child who was born in the natural way. Flanagan (2014) also points out that it is typical for the analyzed genre of literature to include the descriptions of different body transformations. According to Flanagan, (2014, p. 17):

In the context of body modification, child/adolescent characters are routinely depicted as disempowered or subordinated subjects. Decisions regarding these modifications are made by either parents, legal guardians or the state - and the role of the young protagonist is to come to terms with their body and the scientific engineering that has affected or produced it." (Flanagan 2014, p. 17)

This citation finds its confirmation in the negative feelings of Ria.

Similar to Tara, Ria suffers from the inferiority complex caused by the fact that she lacks a navel. For her, it is a sign that differentiates her from others and which makes her feel embarrassed. Even her best friend Tara has mixed emotions when she looks at Ria's body. The author writes:

Tara decided that the siblings must have had plastic surgery. That had to be it. It had to be a fashion statement - part of their 'slant' - and exactly the kind of bizarre lifestyle choice their bizarre mother would support (Menon, 2009, p. 59).

In addition to the complex of inferiority, Ria has a strange feeling instead to her mother. In the initial part of the novel, she is described as a good daughter of an amazing woman who steals everybody's admiration. However, with the development of the plot, this idea undergoes certain transformation because it becomes clear that the relationships in Ria's family are rather complicated.

The girl understands that Vispala (the name via which Mandria is known to the children) came to India with the mission to corrupt the government and to leave a significant number of people without work and money. It creates a conflict between Vispala and Ria and ruins their relationship. In her conversation with Tara, Ria bitterly argues that "Mother is a monster," said Ria. "And so are we" (Menon, 2009, p. 62). The conflict between the mother and the daughter reaches its climax in the middle of the novel when Ria understands that she does not want to return to Nurth. The girl realises that in the world she was born, adults use children as the tool for satisfying their ambitions. She argues that:

What adults brought together, they could (and often did) just as arbitrarily separate. They cared little about their children's friendships or attachments to places or any of the warm and fuzzy stuff. It was all about money and running like mad dogs from one goalpost to the next" (Menon, 2009, p. 64).

This bitter revelation becomes incredibly difficult for Ria when she befriends Tara. She observes there are adults who take care of their children without expecting any returns. Such adults spend time with children simply because they love them.

It should be mentioned that the reaction of children to any modifications or to the feature 
that make them different from others can considerably vary. This statement can be illustrated by the analysis of modes of behaviour Ria and Francis'. While Ria is ashamed of her peculiarity, Francis demonstrates aggression towards those who are not like him. He considers himself to be superior to other people and allows himself to make claims which can be called racist. In one of the scenes described in the novel, Francis openly insults Tara by calling her "sap." Even though Tara does not understand what this word means, Ria explained to her that "sap" is a rude word used by the Nurthi's to humiliate those who live outside their island, who do not have access to new technology, and who do not represent the ruling elite.

The girl mentions that "No... It's short for sapien. Homo Sapiens. Saps. That's how some of the Nurthi refer to non Nurthi. Stupid saps. Lazy saps. You know" (Menon, 2009, p. 62). Having identified himself with the privileged group, Francis believes that he has a right to use insulting words and expressions referring to the people he calls his friends.

The development of the conversation reveals the even more radical attitude of Francis to ordinary human beings. One of the most striking claims given by Francis is the following one: "What's the best way to kill all humans?" "What?" asked Tara, quietly. "Introduce them to each other" (Menon, 2009, p. 61). Francis tried to justify his horrible statements by saying that it was nothing but a joke. However it is clear to the readers that extermination of people is acceptable for the lad. In this respect, Francis' behaviour and his words can be an outcome of the traumatic experience; since he was exposed in his early childhood to body modification and unnatural birth.

Ria and Francis can be called models of new literary characters which typical for young adult science fiction. They experience the intrusion of the technologies which modified their body, and it had an undeniable impact on their lives. Despite their privileged life, Ria and Francis feel that they differ from other people, which causes psychological disorders. Ria suffers from the inferiority complex and hatred towards her mother. Francis demonstrates a high level of aggression to the representatives of various social and cultural groups. In this way, the author promotes the idea according to which any technological intrusion into the process of childbearing and child conception is dangerous because it can bring a significant number of psychological and even physical problems. The following section discusses about the identity construction.

\section{Identity Construction in the Novel}

Another aspect which deserves exclusive analysis is the method of identity construction. The scholars indicate that:

Adolescence is often constructed in terms of its "otherness" or liminality within this genre, and thus parallels the alignment of the posthuman with "otherness" (Flanagan, 2014, p. 18).

This citation is definitely authentic of Menon's book. His adolescent characters have to live in the conditions in which people tend to abandon their true identities and to create new ones. The adult characters of the book pretend, lie, and try to accommodate to reality where human personality is no longer validated.

The central conflict of the novel is the covert war between people representing two opposing groups. The first group comprises Sivan-bhau and his supporters, and these are people who advocate genetic engineering for the public good. Initially, they work secretly and have to conceal their true intentions and their personalities. The second group is represented by Vispala/Mandira, and these people insist on monopolising the IPR (Intellectual Properties Rights) for the use of big corporations. Being sure that genetic engineering is the future of the planet, they want to keep technology only to themselves and to grab new territories by selling such products as Pure Grain. This is an innovation created by the combination of genetic engineering and computer technologies, and the author describes this technology in the following way: 
Seed + software. Suppose you want a field of wheat? Or barley? Or maybe you want oats? No problem. Pure Grain seeds can be made to produce all three grains. You merely have to run different programs on the seeds. The programs are specified via the fertilizer. Some such thing. You run the appropriate programs, and one batch of Pure Grain will develop into rice, another into wheat, a third into barley, oats, whatever you want. (Menon, 2009, p. 62)

Even though this product has the potential to solve a significant number of human problems such as hunger or food crisis, its monopolisation will bring nothing except for further deterioration of living conditions for billions of people. The problem is that it will push from the market almost all farmers, since crops will be grown only by the companies which can buy an expensive Pure Grain technology. Besides, the price of seeds will be relatively high, and it means that people in developing nations will have to spend all their money on food. They will be turned into food slaves controlled by big business and foreign governments. Sivan Bhau's fear is the same of Neil Holtzman, who coined the term Genohype and explicates, "exaggerating the importance of genetic factors stops people thinking about the need to clean up the environment and tackle socioeconomic inequity" (Holtzman, as cited in Zurr\&Catt, 2005) Furthermore, it becomes clear that the main aim of Vispala is to gain immortality, and because of this, she insists on the overwhelming development of genetic engineering. Even though Sivan-bhau and Vispala/Mandira have different aims, they employ the same strategy of hiding their true identity. They protect the information about their meeting long before Tara and the twin were born. The adults do not tell their children that they are the result of the experiments aimed at expanding their lifespan and at gaining potential immortality.

Sivan-bhau does the research for scientific development and for advancement of human life whereas, Vispala/Mandira do it for power and control over the people and government, but it definitely influences their children who are taught to lie by the real-life examples of their parents. This is especially true in the case of Aditya's who has to face the consequences of the scientific experiment, born with dyslexia. The experiments conducted by his father triggers negative moments in the young man's life, thus became the reason of his humiliation and rebellion. These experiments also made it difficult and painful to construct Adi's identity since, not knowing the truth he could not understand who he really was. In this way, the author of the book shows that in the world of extensive experiments with nature, there can hardly be any positive characters. Even Sivanbhau, a real genius of biology, is responsible for ruining his son's life and this fact proves once again that transhumanism is a problematic philosophy because it hides a significant number of challenges and threats which people do not know how to solve and face.

\section{Conclusion}

This study has critically analysed The Beast with Nine Billion Feet which is one of the most popular books dealing with the problem of transhumanism and its potential threats. Choosing two families, the author shows that this new trend of human development can be rather dangerous, especially for children because it deprives them the chance to make conscious decisions about their bodies. Being created as the results of various experiments, such children have psychological disorders which find their manifestation in dyslexia, depression, inferiority complex, or a high level of aggression. Besides, such children have problematic relationships with members of their families, and it is difficult for them to find their true identity. In this respect, the novel can be interpreted as a warning of the author against an absorbing obsession with such popular sciences as genetic engineering.

\section{References}

Agar, N. (2007). Where to Transhumanism? The Literature Reaches a Critical Mass. Hastings

Center Report, 37(3), 12-17. doi:

10.1353/hcr.2007.0034 
Alighieri, D. (2003). Divine Comedy. New York: Barnes and Noble Classics.

de La Mettrie, J. O. (1912). Man a machine. Open Court.

Dow, S., \& Wright, C. (2010). Introduction:

Towards a Psychoanalytic Reading of the Posthuman. Paragraph, 33(3), 299-317. doi: 10.3366/para.2010.0201

Flanagan, V. (2014). Technology and Identity in Young Adult Fiction. London: Palgrave Macmillan.

FM-2030. (1989). Are You A Transhuman?. New York, NY: Warner Books.

Gelles, D. (2020). Immortality 2.0: A Silicon

Valley Insider Looks at California's

Transhumanist Movement.

https://web.archive.org/web/20120512223654

/http://ce399eugenics.wordpress.com/2010/06 /19/immortality-2-0-a-silicon-valley-insiderlooks-at-californias-transhumanist-movement/

Graham, E. (2002). 'Nietzsche Gets a Modem': Transhumanism and the Technological Sublime. Literature And Theology, 16(1), 65-80. doi: 10.1093/litthe/16.1.65

Hayles, N. K. (1993). The Seductions of Cyberspace. In Conley, VerenaAndermatt (ed). Rethinking Technologies. University of Minnesota Press, pp. 173-190.

Hughes, J. (2013). Transhumanism and Personal Identity. In More, M. and Vita-More (ed). The Transhumanist Reader: Classical and Contemporary Essays on the Science, Technology, and Philosophy of the Human Future.N.John Wiley \& Sons, 227-233

Huxley, J. (1967). Religion without Revelation. Watts.

Menon, A., (2009). The Beast with Nine Billion Feet. Zubaan books.

Mercer, C. (2014). Religion and Transhumanism: The Unknown Future of Human Enhancement, Praege.

More, M. (1995). The Diachronic Self: Identity, Continuity, Transformation. A Bell\& Howell Company. www.maxmore.com/disscont.htm
More, M., \& Vita-More, N. (Eds.). (2013). The

Transhumanist Reader: Classical and

Contemporary Essays on the Science, Technology, and Philosophy of the Human Future. John Wiley \& Sons.

Transhumanism: into the future by the razor's edge. Idea and prospects. - Steemit. (2019). https://steemit.com/science/@kuku12170/tran shumanism-into-the-future-by-the-razor-sedge-idea-and-prospects

Zurr, I., \& Catts, O. (2005). Big Pigs, Small Wings: On Genohype and Artistic Autonomy. Culture Machine. 7

https://culturemachine.net/biopolitics/big-pigssmall-wings/

\section{Conflict of Interest Statement}

We, Narendiran S and Bhuvaneswri R of Vellore Institute of Technology, Chennai, certify that we do not have any affiliations or involvement with any organisation or entity with any financial or non-financial interest in the subject matter discussed in the manuscript, The Uninhibited Evolution of the Human Persona: A Transhumanistic Study of Anil Menon's The Beast with Nine Billion Feet.

\section{Acknowledgements}

We would like to thank the anonymous reviewers for reviewing the paper critically and giving helpful comments that helped in giving clarity to the paper.

\section{Author Contribution Statement}

Narendiran $S$ has conceptualised, collected resources, analysed and wrote the original draft. Dr Bhuvaneswari $\mathrm{R}$ is the corresponding author and supervisor. She edited, reviewed and developed the final draft. 